\title{
Immunohistochemical Characterization of Macrophages and Myofibroblasts in Fibrotic Liver Lesions Due to Fasciola Infection in Cattle
}

\author{
Hossain M. GOLBAR ${ }^{1)}$, Takeshi IZAWA ${ }^{1)}$, Vetnizah JUNIANTITO' ${ }^{1)}$, Chisa ICHIKAWA ${ }^{1)}$, Miyuu TANAKA ${ }^{1)}$, \\ Mitsuru KUWAMURA ${ }^{1)}$ and Jyoji YAMATE ${ }^{1) *}$ \\ 1) Veterinary Pathology, Graduate School of Life and Environmental Sciences, Osaka Prefecture University, 1-58 Rinku-ourai-kita, \\ Izumisano City, Osaka 598-8531, Japan
}

(Received 10 December 2012/Accepted 2 February 2013/Published online in J-STAGE 15 February 2013)

ABSTRACT. Histopathologically, fibrosis in Fasciola-infected cattle livers was characterized by inflammatory cell infiltration, such as eosinophils and macrophages, pseudo-lobule, pseudo-bile ducts and fibrotic bridges separating pseudo-lobules; the fibrotic lesions were developed in the Glisson's sheath. Pseudo-bile ducts consisting of epithelial cells reacted clearly to cytokeratin (CK) 19, indicating cholangiocyte origin. Immunophenotypes of macrophages and myofibroblasts were investigated in the fibrotic livers. Macrophages positive for CD68 (reflecting phagocytosis) and CD163 (representing proinflammatory cytokine production) were increased, and those for CD204 (implying lipid metabolism) and Iba-1 (a calcium-binding protein playing role in chemotaxis) decreased in fibrotic livers compared to control livers. Spindle-shaped myofibroblasts positive for vimentin, desmin and $\alpha$-smooth muscle actin ( $\alpha$-SMA) increased in the peribiliary connective tissues, although the desmin-positive cells were fewer. In addition to the usefulness of these antibodies for macrophage detection in cattle livers, this study shows that macrophages with different immunophenotypes participate in Fasciola-infected cattle livers, in relation to development of myofibroblasts expressing mainly vimentin and $\alpha$-SMA. KEY WORDS: biliary fibrosis, cattle, liver, macrophages, myofibroblasts.

doi: 10.1292/jvms.12-0536; J. Vet. Med. Sci. 75(7): 857-865, 2013

Biliary fibrosis is the outcome of wound healing responses due to persistent or repeated injuries to cholangiocytes in cholangiopathies [23, 34]. Uncontrolled biliary fibrosis progresses toward cirrhosis which is characterized by diffuse nodular fibrotic lesions throughout liver tissues; the advanced conditions should culminate in hepatic insufficiency [47]. Cholangiopathies in humans, such as sclerosing cholangitis, drug-induced cholangiocyte damage, autoimmunity and obstruction of bile ducts due to cholelithiasis, have been implicated in abnormal remodeling of bile ducts leading finally to biliary fibrosis in the Glisson's sheath. In veterinary medicine, along with aforementioned causes, liver fluke (Fasciola spp.) infections are important for hepatic failure in cattle. In the infection, hepatocyte damage is caused by migration of immature parasites at the acute stage; then, adult parasites invade bile ducts in the Glisson's sheath and settle within the ducts at the chronic stage [1]. The infection causes cholangitis, cholangiocyte hyperplasia and biliary fibrosis, and cirrhosis may be developed in cattle with severe and persistent infection [28]; this condition may result in poor weight gain, reduced milk and meat yield, and infertility at the final stage $[22,30]$. Such significant economic loss due to liver fluke infection is a major public health problem in some parts of the world, especially in East Asia, East Eu-

\footnotetext{
*Correspondence to: Yamate, J., Veterinary Pathology, Graduate School of Life and Environmental Sciences, Osaka Prefecture University, 1-58 Rinku-ourai-kita, Izumisano City, Osaka 5988531, Japan.

e-mail: yamate@vet.osakafu-u.ac.jp

(C)2013 The Japanese Society of Veterinary Science
}

rope, Africa and Latin America [26, 27, 50]. However, the pathological events in liver fluke infection-associated biliary fibrosis have not been investigated in detail at cellular levels, although the appearance of eosinophils is well known [28].

Fibrosis is a complex process characterized by inflammatory cell infiltrates and excessive deposition of extracellular matrices (ECMs). Out of the inflammatory cells, macrophages play a central role in fibrogenesis via production of fibrogenic factors [2, 43]; the most effective factor is transforming growth factor- $\beta$ (TGF- $\beta$ ) [19]. The macrophages appearing in fibrotic lesions induced in rats by hepatotoxicants have been demonstrated to be heterogeneous in immunophenotypes [18]. Based on immunoexpressions with different antibodies for macrophages, these cell types in rat hepatic fibrosis have properties, such as phagocytic activity, proinflammatory factor production and MHC class II expression [29]. These hepatic macrophages may be recruited from Kupffer cells, blood monocytes and interstitial dendritic cells present in the Glisson's sheath $[11,29]$. The ECMs are produced by myofibroblasts. In the hepatic fibrosis after parenchymal injury, myofibroblasts have been considered to be derived from hepatic stellate cells (HSCs) $[9,14]$. On the other hand, pre-existing fibroblasts may be the precursor of myofibroblasts in biliary fibrosis [3, 12, 37]. The myofibroblasts can express various cytoskeletons, such as vimentin, desmin and $\alpha$-smooth muscle actin ( $\alpha$-SMA). The cellular properties have not yet been characterized in liver fluke infection-induced biliary fibrosis in cattle.

In order to shed some light behind the pathogenesis of biliary fibrosis, in this study, we investigated the properties of macrophages and myofibroblasts in liver fluke infectioninduced cattle liver lesions by using the immunohistochem- 
Table 1. Primary antibodies used for immunohistochemistry

\begin{tabular}{|c|c|c|c|c|c|}
\hline Antibody & Clone & $\begin{array}{l}\text { Dilu- } \\
\text { tion }\end{array}$ & $\begin{array}{l}\text { Antigen } \\
\text { retrieval }\end{array}$ & Source of antibody & Specificity \\
\hline Anti-CD68 & EMB11 & $1: 50$ & Proteinase K & DakoCytomation, Glostrup, Denmark & Exudate macrophages \\
\hline Anti-CD163 & AM-3K & $1: 50$ & Proteinase K & TransGenic Inc., Kumamoto, Japan & Resident macrophages (Kupffer cells) \\
\hline Anti-CD204 & SRA-E5 & $1: 100$ & Heat & TransGenic Inc. & Macrophages, Kupffer cells \\
\hline *Anti-Iba-1 & - & $1: 100$ & Heat & Wako Pure Chemical Industries Ltd.., Osaka, Japan & Macrophages \\
\hline Anti-vimentin & V9 & $1: 400$ & Heat & DakoCytomation & Cells of mesenchymal origin \\
\hline Anti- $\alpha-S M A$ & $1 \mathrm{~A} 4$ & $1: 100$ & Proteinase K & DakoCytomation & Smooth muscle cells, myofibroblasts \\
\hline Anti-CK19 & b170 & $1: 100$ & Trypsin & Novocastra Laboratories Ltd., Newcastle, UK & Cholangiocytes \\
\hline
\end{tabular}

*; Rabbit polyclonal antibody; the others are mouse monoclonal antibodies. $\alpha$-SMA: $\alpha$-smooth muscle actin; CK19: cytokeratin 19.

istry with a panel of antibodies for detection of macrophages and myofibroblasts. This study shows that macrophages with heterogenous phenotypes participate in the lesions, and myofibroblasts express various mesenchymal cytoskeletons, particularly vimentin and $\alpha$-SMA.

\section{MATERIALS AND METHODS}

Samples: Fasciola-infected adult cattle livers involving biliary fibrosis $(n=8)$, termed as fibrotic livers, obtained at 2 abattoirs in Osaka, Japan were used in this study. Normal tissues $(n=4)$ distant from the lesions served as control livers. Macroscopic examination of the affected areas of the fibrotic livers revealed whitish discoloration, surface irregularity, thinning of edge, firmness in cutting and Fasciola spp. in the bile ducts on the cut surface. The study protocol conformed to the institutional guidelines of Osaka Prefecture University for handling and use of biological specimens for experimental purposes.

Histopathology and immunohistochemistry: Fibrotic and control liver tissues were fixed in $10 \%$ neutral buffered formalin and Zamboni's fixative $(0.21 \%$ picric acid and $2 \%$ paraformaldehyde in $130 \mathrm{mM}$ phosphate buffer, $\mathrm{pH}$ 7.4) [17]. These tissues were dehydrated and embedded in paraffin. Formalin-fixed deparaffinized sections of $4 \mu \mathrm{m}$ thick were stained with hematoxylin and eosin (HE) and AzanMallory methods for histopathology. The Zamboni-fixed, deparaffinized sections were used for all immunohistochemical staining with monoclonal mouse anti-CD68, antiCD163 (AM-3K) and anti-CD204 (SRA-E5; a macrophage scavenger receptor) antibodies, as well as rabbit polyclonal anti-ionized calcium binding adaptor molecule-1 (Iba-1), antibody for macrophages; monoclonal mouse anti-vimentin, anti-desmin and anti- $\alpha$-SMA antibodies for mesenchymal cells/myofibroblasts; monoclonal mouse anti-cytokeratin (CK) 19 antibody for bile duct epithelial cells. The detail information of these antibodies is given in Table 1.

After antigen retrieval with heat (microwave in citrate buffer for $20 \mathrm{~min})$, trypsin $(0.1 \%$ trypsin in phosphate buffered saline (PBS) for $30 \mathrm{~min}$ at $37^{\circ} \mathrm{C}$ ) or proteinase $\mathrm{K}$ $(10 \mu \mathrm{g} / \mathrm{m} l$ proteinase $\mathrm{K}$ in Tris- $\mathrm{HCl}(50 \mathrm{mM}, \mathrm{pH} 7.5)$ for $15 \mathrm{~min}$ ) as shown in Table 1, tissue sections were treated with $3 \% \mathrm{H}_{2} \mathrm{O}_{2}$ in PBS to quench endogenous peroxidase and
Table 2. Semi-quantitative analyses of hepatic stellate cells/myofibroblasts

\begin{tabular}{lcccc}
\hline Sample & PP CL & PV CL & PCT FL & PSL FL \\
\hline$\alpha$-SMA & \pm & + & $++\sim+++$ & + \\
Vimentin & $\pm \sim+$ & $\pm \sim+$ & $++\sim+++$ & \pm \\
Desmin & \pm & \pm & + & - \\
\hline
\end{tabular}

PP: periportal (including the Glisson's sheath); CL: control liver; PV: perivenular; PCT: portal connective tissue; FL: fibrotic liver; PSL: pseudo-lobule.

Semi-quantitative grades: - , no positive cells; \pm , few positive cells; +, small number positive cells; ++, moderate number positive cells; +++, many positive cells.

then with 5\% skimmed milk in PBS to inhibit nonspecific reactions. The sections were incubated with each primary antibody overnight ( 2 overnights for anti-CD163 antibody) at $4^{\circ} \mathrm{C}$, followed by reaction with the secondary antibody (Histofine Simple Stain MAX-PO, Nichirei, Tokyo, Japan). Positive reactions were visualized with 3, 3'-diaminobenzidine (DAB Substrate Kit, Vector Laboratories, Inc., Burlingame, CA, U.S.A.). Sections stained with non-immunized mouse or rabbit serum instead of primary antibodies were all negative, and served as a negative control. Sections were counterstained lightly with hematoxylin.

Cell count and statistical analyses: Cells showing a distinct immunopositive reactions for CD68, CD163, CD204 and Iba- 1 were counted in 5 randomly selected areas $(0.2$ $\mathrm{mm}^{2}$ ) of each sample at the periportal (including the Glisson's sheath) and perivenular areas of the control livers, as well as portal fibrotic tissues and pseudo-lobules of the fibrotic livers at a magnification of $400 \times$ using ImageJ software version 1.44 (NIH, Bethesda, MD, U.S.A.). Cells positive for vimentin, desmin and $\alpha$-SMA were evaluated semi-quantitatively using grades as shown in Table 2. Obtained data represented mean \pm standard deviation (SD), and statistical analysis was performed using student's $t$-test. Significance was set at $P<0.05$.

\section{RESULTS}

Histopathology: As control liver tissues, the authors used portions without any lesions (Fig. 1A). Grossly, the liver 

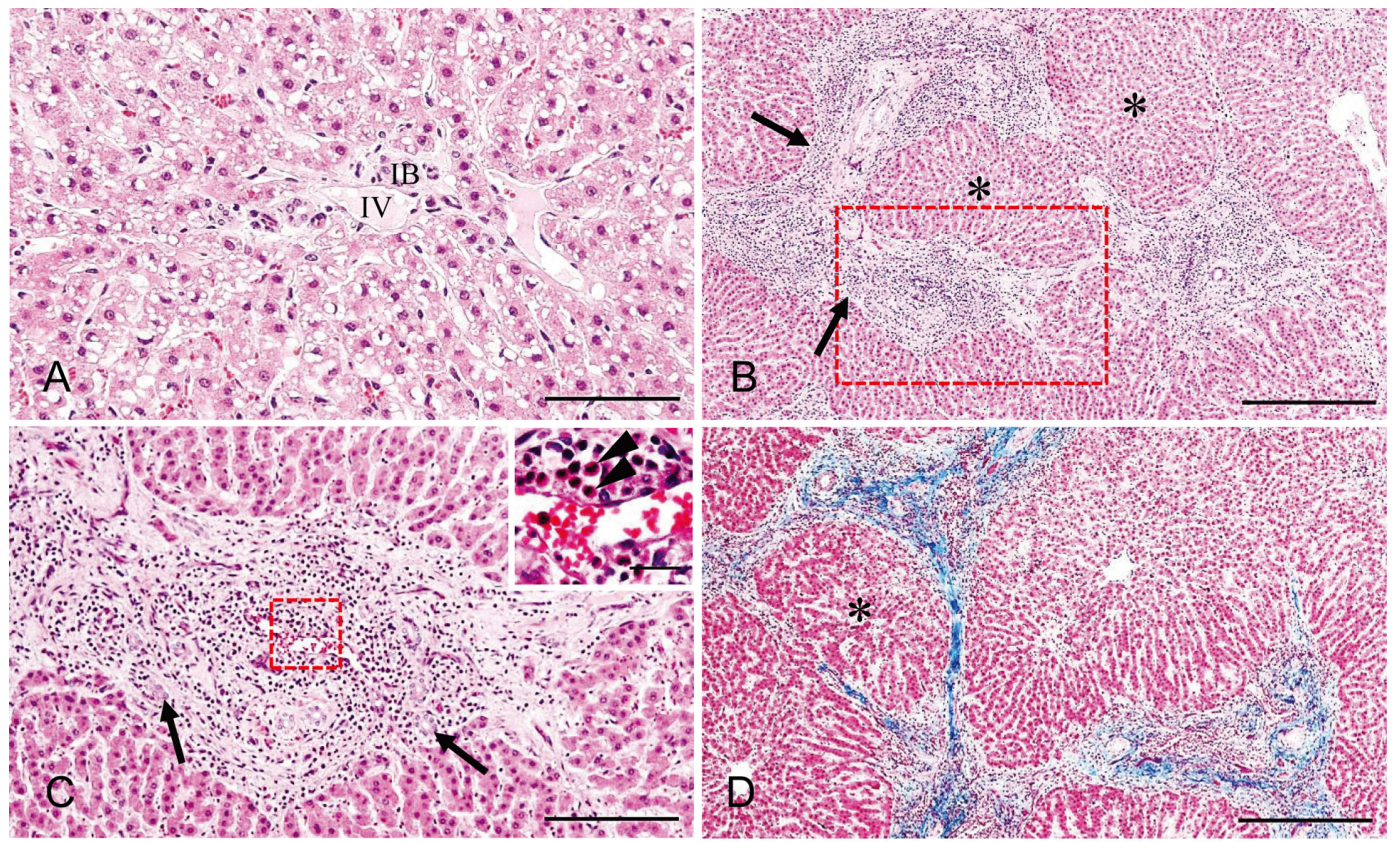

Fig. 1. Fasciola-induced biliary fibrosis, cattle. Histopathology of Fasciola-induced biliary fibrosis. (A) Control liver showing no apparent changes. (B) Fibrotic liver section shows prominent fibrosis in the Glisson's sheath, fibrotic bridges between adjacent portal areas (arrows), formation of pseudo-lobules (asterisks) and infiltration of inflammatory cells. (C) The affected Glisson's sheath (a higher magnification of outlined area in B) consists of bile duct hyperplasia (arrows) and the inflammatory cells such as eosinophils (inset, arrowheads). (D) Fibrotic tissues, demonstrable with collagen staining (blue), around a pseudo-lobule (asterisk) and in the portal to portal bridge are seen. IB: interlobular bile duct, IV: interlobular vein. HE. Bar=100 $\mu \mathrm{m}$ (A); $500 \mu \mathrm{m}$ (B); $200 \mu \mathrm{m}$ (C), $20 \mu \mathrm{m}$ (inset of C); Azan-Mallory. Bar $=500 \mu \mathrm{m}(\mathrm{D})$.

fluke-infected areas of the fibrotic livers had irregular surface, and there were liver flukes in some dilated bile ducts. Histopathologically, the lesions consisted of fibrosis with pseudo-lobule formation. The fibrotic lesions were composed of inflammatory cells, spindle-shaped cells and deposition of collagen fibers, forming bridges by which pseudo-lobules were separated (Fig. 1B). The greatest fibrotic lesions were found to be developed exclusively in the Glisson's sheath, because there were interlobular veins, interlobular arteries and interlobular bile ducts. Eosinophils were frequently seen in the fibrotic lesions (Fig. 1C, inset), and mononuclear cells were also observed often. The deposition of collagen fibers forming bridges was clearly demonstrated by Azan-Mallory methods (Fig. 1D). In addition to the ductular reaction, called pseudo-bile ducts, in the affected Glisson's sheath, newly-formed blood vessels were frequently seen. Based on histopathological findings, the liver fluke-infected fibrotic lesions were regarded as biliary fibrosis at the advanced stage.

Macrophage immunophenotypes: The numbers of macrophages positive for CD68, CD163, CD204 and Iba-1 were counted in control and fibrotic livers, and the statistical evaluation data are presented in Fig. 2. In control livers, the numbers of macrophages reacting to CD68 (Fig. 2A), CD163 (Fig. 2B), CD204 (Fig. 2C) and Iba-1 (Fig. 2D) were all greater in the periportal areas (including the Glisson's sheath) than those of perivenular areas. On the other hand, in fibrotic livers, the numbers of macrophages reactive for CD68 (Fig. 2A) and CD163 (Fig. 2B) were higher in the portal connective tissues compared to those in the parenchyma in the pseudo-lobules. By contrast, the numbers of macrophages positive for CD204 (Fig. 2C) and Iba-1 (Fig. 2D) were lower in the portal connective tissues compared to those in the pseudo-lobules. We compared the average number between control and fibrotic livers; overall, macrophages expressing CD68 and CD163 in the fibrotic livers were significantly increased in contrast to those in the control livers (Fig. 2A, B); on the other hand, those positive for CD204 and Iba-1 showed a significant decrease in fibrotic livers than control livers (Fig. 2C, D).

In the control livers, CD68-, CD163-, CD204- and Iba1-positive macrophages were sporadically distributed in the hepatic parenchyma and the periportal areas (including the Glisson's sheath) (Fig. 3A, C, E, G, respectively). The cytoplasm of the CD204-positive macrophages appeared to be slightly enlarged (Fig. 3E) in contrast to macrophages reacting to CD68, CD163 and Iba-1. Based on the distribution of these macrophages, it was considered that Kupffer cells located along the sinusoids of the liver lobules and tissue macrophages in the Glisson's sheath reacted to these antibodies in varying degrees. In fibrotic liver tissues including the Glisson's sheath, macrophages reacting to CD68 (Fig. 

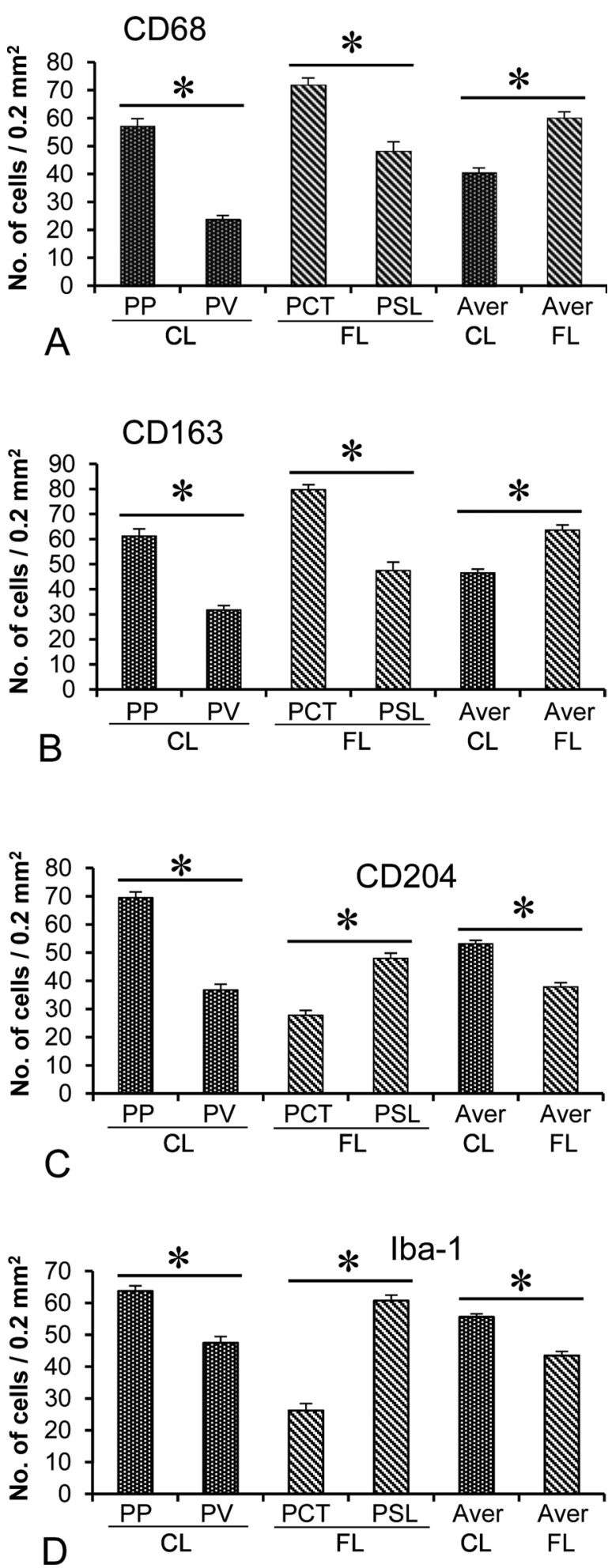

3B), CD163 (Fig. 3D), CD204 (Fig. 3F) and Iba-1 (Fig. 3H) were often seen; particularly, the numbers of cells reacting to CD68 and CD163 were greater in fibrotic livers as mentioned in the statistical evaluation (Fig. 2A-D).

Immunophenotypes of mesenchymal cells and myofibroblasts in the Glisson's sheath: Semi-quantitative analysis on the expressions of vimentin, desmin and $\alpha$-SMA in control and fibrotic livers is presented in Table 2. Pre-existing and newly-formed vascular smooth muscles were reactive for desmin and $\alpha$-SMA, which thus were excluded from the evaluation. In control livers, spindloid cells reacting to vimentin (Fig. 4A), desmin (Fig. 4C) and $\alpha$-SMA (Fig. 4E) were present along the sinusoid, indicating that HSCs in cattle react to these antibodies as mesenchymal markers. Additionally, vimentin-positive cells seen in the Glisson's sheath are considered to be pre-existing mesenchymal cells/ portal fibroblasts; on the contrary, desmin and $\alpha$-SMApositive cells were rarely seen in the Glisson's sheath.

In the fibrotic liver tissues including the Glisson's sheath, mesenchymal cells reacting to vimentin (Fig. 4B), desmin (Fig. 4D) and $\alpha$-SMA (Fig. 4F) were seen more frequently. Particularly, vimentin and $\alpha$-SMA-positive cells (Fig. 4B, $4 \mathrm{~F}$, respectively) were greater than that of desmin-positive cells (Fig. 4D) in the fibrotic livers. Interestingly, $\alpha$-SMApositive cells appeared surrounding the hyperplastic interlobular bile ducts (Fig. 4F, arrows). As mentioned above, smooth muscle cells in newly formed blood vessels reacted strongly to $\alpha$-SMA (Fig. 4F, arrowheads).

Immunohistochemistry for cholangiocytes: Immunoreactivity for CK19, a marker of cholangiocyte, was limited to the epithelial cells of interlobular bile ducts in the Glisson's sheath in the control livers (Fig. 5A). By contrast, CK19immunopositive cholangiocytes in the interlobular bile ducts involved in the fibrotic livers were clearly seen (Fig. 5B). Additionally, CK19-positive cells were observed in the fibrotic livers; some of them were sporadically present as a single cell or clusters consisting of a few cells, and the others formed ducts without clear lumen (Fig. 5C). Therefore, the frequency of CK19-positive cholangiocytes was increased in the fibrotic livers.

\section{DISCUSSION}

Histopathology: Biliary fibrosis is the subtype of hepatic fibrosis which is frequently associated with ductular reactions (hyperplasia/proliferation which form pseudo-bile ducts) and structural alteration [24, 40]. The biliary fibrotic lesions of the present cattle were characterized by pseudolobule formation, proliferation/hyperplasia of bile ducts and fibrotic bridges. The fibrotic bridges were formed between

Fig. 2. Fasciola-induced biliary fibrosis, cattle. The kinetics of macrophages reacting to CD68, CD163, CD204 and Iba-1 in the biliary fibrosis. (A-D) In control liver (CL), macrophage populations are greater in the periportal (PP) areas than those in the perivenular (PV) areas. (A-B) In fibrotic liver (FL), macrophages positive for CD68 and CD163 are greater in the portal connective tissues (PCT) than those in the parenchyma of pseudo-lobule (PSL). (C-D) By contrast, macrophages reactive for CD204 and Iba-1 are smaller in PCT than those in the parenchyma of PSL. Compared to CL, the numbers of macrophages positive for CD68 and CD163 are increased and those for CD204 and Iba-1 are decreased in FL. Aver: Average. Student's $t$-test. $* P<0.05$. 


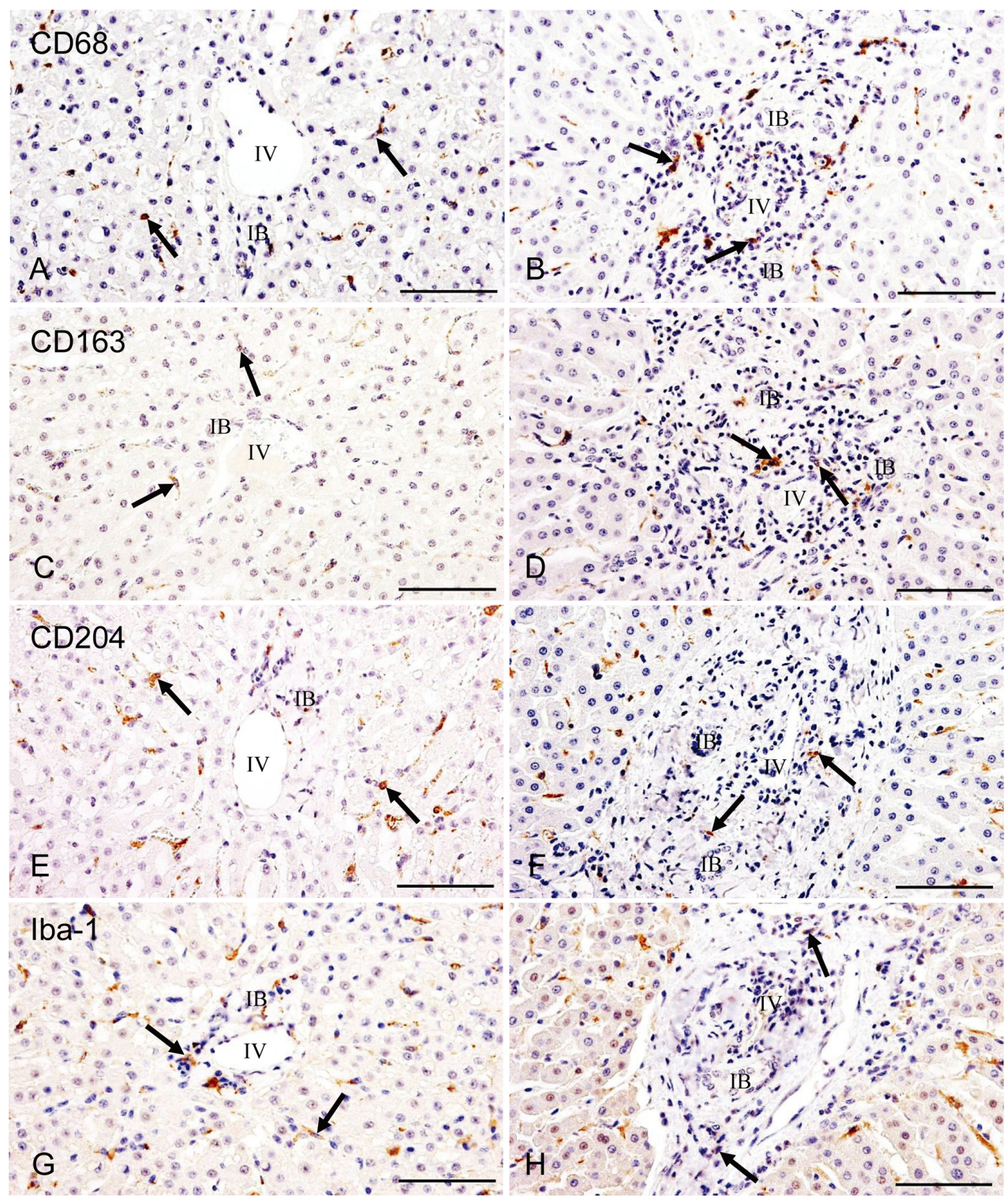

Fig. 3. Fasciola-induced biliary fibrosis, cattle. The distributions of macrophages positive for CD68, CD163, CD204 and Iba-1 in the biliary fibrosis. (A, C, E, G) Immunopositive macrophages are sporadically distributed in the periportal areas including the Glisson's sheath in control livers. (B, D) A number of macrophages positive for CD68 and CD163 are detectable in the portal connective tissues (PCT) in fibrotic livers (FL). (F, H) Only a few macrophages reactive for CD204 and Iba-1 are present in the PCT in FL. IB: interlobular bile duct, IV: interlobular vein. Arrows indicate representative cells in each staining. Immunohistochemistry, counterstained with hematoxylin. Bar=100 $\mu \mathrm{m}$.

portal and portal areas, between portal and central vein areas or central vein and central vein areas [39]. Ductular reaction is regarded as "pacemaker of portal fibrosis" and used as an indicator for assessment of degrees of hepatic fibrosis [5, 34, 38]. In the current study, marked ductular reaction was observed by the immunoreactivity with CK19 antibody, indicating the advanced stage of hepatic fibrosis for the present cases examined. The ductular reaction may be derived from metaplasia of hepatocytes without function [49]. A single epithelial cell and cellular clusters consisting of a few epithelial cells, which were reactive for CK19, may be metaplastic cells of hepatocytes, because cholangiocytes 


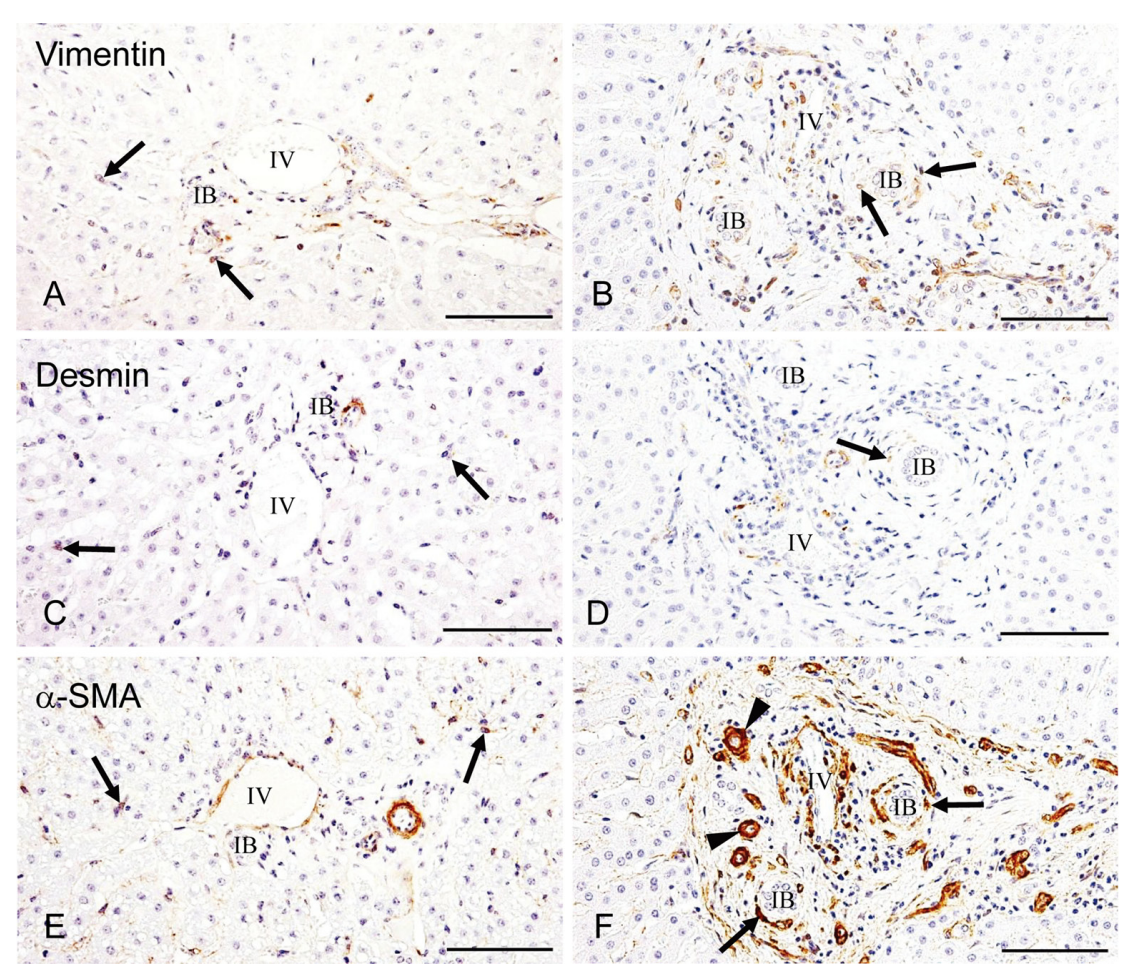

Fig. 4. Fasciola-induced biliary fibrosis, cattle. The distributions of mesenchymal cells/myofibroblasts positive for vimentin, desmin and $\alpha$-SMA in the biliary fibrosis. (A, C, E) A few cells expressing vimentin, desmin and $\alpha$-SMA are seen in the periportal areas (including the Glisson's sheath) in the control livers. (B, D, F) In contrast to control livers, the numbers of cells expressing vimentin, desmin and $\alpha$-SMA are increased in the Glisson's sheath in fibrotic livers. (D) Note that desmin-expressing cells are relatively fewer, and (F) newly-formed blood vessels in the Glisson's sheath, reactive for $\alpha$-SMA (arrowheads), are seen. IB: interlobular bile duct, IV: interlobular vein. Arrows indicate representative cells in each staining. Immunohistochemistry, counterstained with hematoxylin. Bar $=100 \mu \mathrm{m}$.
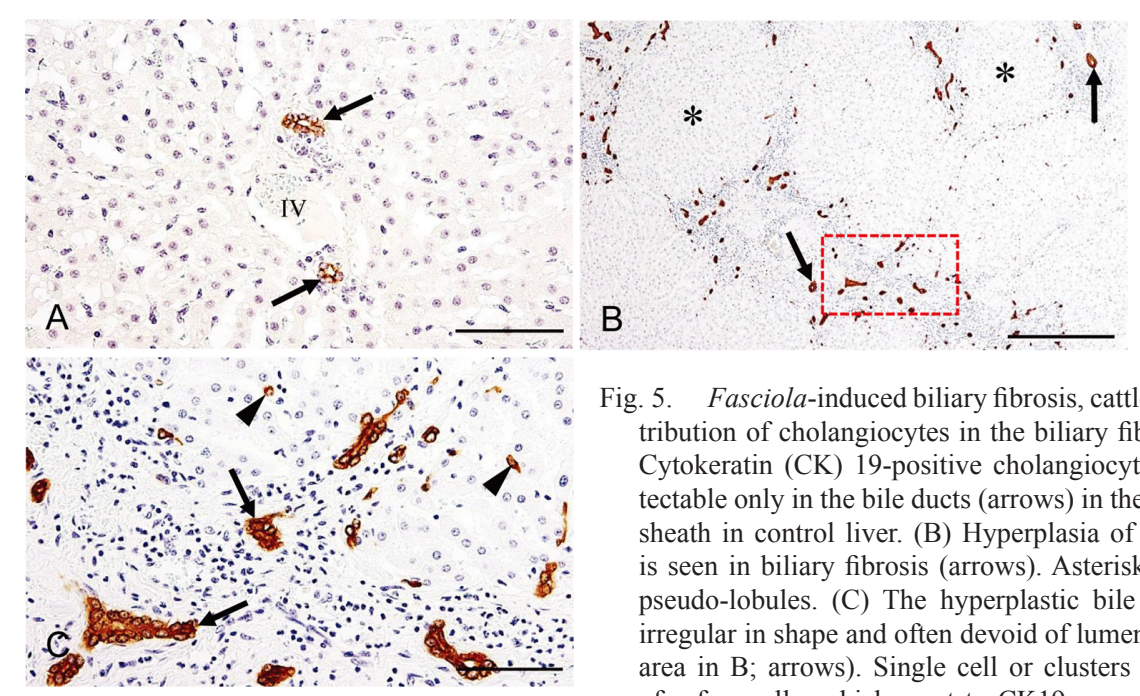

Fig. 5. Fasciola-induced biliary fibrosis, cattle. The distribution of cholangiocytes in the biliary fibrosis. (A) Cytokeratin (CK) 19-positive cholangiocytes are detectable only in the bile ducts (arrows) in the Glisson's sheath in control liver. (B) Hyperplasia of bile ducts is seen in biliary fibrosis (arrows). Asterisks indicate pseudo-lobules. (C) The hyperplastic bile ducts are irregular in shape and often devoid of lumen (outlined area in B; arrows). Single cell or clusters consisting of a few cells, which react to CK19, are seen in the periportal parenchyma (arrowheads). IV: interlobular vein. Immunohistochemistry, counterstained with hematoxylin. Bar=100 $\mu \mathrm{m}$ (A, C), $500 \mu \mathrm{m}$ (B). 
and hepatocytes have been considered to be generated from the common progenitors, termed as oval cells [45, 49]. Periportal region with advancing fibrosis might serve as a niche for the metaplasia of progenitor cells [10].

Macrophages: Eosinophil infiltration was clearly observed as the major inflammatory cell type in the present case as reported previously in cattle livers infected with Fasciola spp. [46]. In addition to eosinophils, mononuclear cells were observed in the fibrotic livers. The mononuclear cells were regarded as macrophages by the present immunohistochemistry. Macrophages have been demonstrated to have crucial roles in fibrogenesis. TGF- $\beta 1$, a potent fibrogenic factor, produced by macrophages can incite myofibroblast development [2, 19, 43]. Previously, the appearance of macrophages has been demonstrated to play roles in Schistosoma-infected livers in mice [48]. The current study showed that macrophages appeared in close proximity with collagen-producing myofibroblasts in the portal connective tissues in Fasciola-induced biliary fibrosis, indicating involvement of macrophages in fibrogenesis due to liver fluke infection (Fascioliasis). Factors produced by cholangiocytes in ductular reaction, which is commonly observed in Fasciola-infected livers, might recruit macrophages in the Glisson's sheath undergoing fibrogenesis $[4,20]$. However, the factors remain to be investigated. In the present study, we attempted to investigate the immunophenotypes of macrophages. In the control livers, macrophages reacting to CD68, CD163, CD204 and Iba-1 were detected along the sinusoids; these findings for the first time showed that these antibodies would be useful for the detection for hepatic macrophages in cattle. Furthermore, the present study demonstrated that macrophages reacting to these antibodies were greater in the number in the periportal areas than in the perivenular areas, indicating that Kupffer cells are more predominant in the periportal areas [33]. CD68 up-expression may imply the activated phagocytosis, because CD68 is located on lysosomal membrane, especially phagolysosome of blood monocyte-derived exudate and resident macrophages [6, 42]. CD163 is a cell-surface glycoprotein receptor, which is highly expressed in resident macrophages [8], and triggers the production of proinflammatory mediators, such as tumor necrosis factor (TNF)- $\alpha$, interleukin (IL)-1 $\beta$ and IL-6 [36], and it may also acts as endocytic scavenger receptor for hemoglobin-haptoglobin complex which can mediate clearance of free hemoglobin from the circulation [13]; therefore, CD163-expressing macrophages may be related to the proinflammatory cytokine production and phagocytosis. CD204 is a principal receptor of macrophages whose major function is to eliminate target ligands, such as modified low density lipoprotein $[15,35,44]$. Iba-1, also known as allograft inflammatory factor-1 (AIF1), is critically involved in motility-associated rearrangement of the actin cytoskeleton [21, 32].

Interestingly, in the fibrotic livers, the numbers of macrophages positive for CD68 and CD163 were significantly greater than those in control livers, whereas macrophages reacting to CD204 and Iba-1 were decreased. Although the reason should be investigated further, macrophages in the fibrotic livers might have been considered to show increased phagocytosis and proinflammatory factor production rather than lipid metabolism and mobility. At least, it was considered that macrophages with different functions might participate in the biliary fibrosis associated with liver fluke infection in cattle. To our knowledge, these investigations on macrophage properties are the first trial for fibrosis in liver fluke-infected cattle.

Myofibroblasts in the Glisson's sheath with fibrosis: Myofibroblasts are identified by immunoexpressions of cytoskeletons, such as $\alpha$-SMA, vimentin and desmin, and the myofibroblasts play important roles in hepatic fibrosis by producing ECMs [16, 25]. HSCs along the sinusoids and pre-existing fibroblasts in the Glisson's sheath may be the precursors of myofibroblasts [3]. The portal fibroblasts are characterized by vimentin positivity but do not react to desmin, and HSCs in normal rat livers are identified by vimentin and desmin reactions [34]. $\alpha$-SMA expression is seen in well-differentiated myofibroblasts in advanced fibrosis $[31,47]$. In the fibrotic lesions of the present cattle, desminpositive cells were infrequently seen, and vimentin-positive cells were moderately or frequently present. Interestingly, $\alpha$-SMA-positive cells were markedly increased in the fibrotic livers. These findings indicated that myofibroblasts expressing $\alpha$-SMA might be derived from the pre-existing portal fibroblasts rather than HSCs, as have been mentioned in rat biliary fibrosis $[3,7]$.

In summary, in addition to the availability of different antibodies (against CD68, CD163, CD204 and Iba-1) for macrophage detection in cattle tissues, this study demonstrates that macrophages immunopositive to these antibodies are present more predominantly in the periportal areas than in the perivenular areas. Furthermore, it was found that CD68- and CD163-positive macrophages participated in the biliary fibrosis of cattle; on the other hand, CD204and Iba-1-positive macrophages were less in number. On the basis of possible functions demonstrable with the immunohistochemistry with these antibodies, macrophages appearing in the fibrotic areas might have properties, such as phagocytosis and proinflammatory factor productions. It was found that myofibroblasts, which are considered to contribute to fibrogenesis, reacted moderately or strongly to vimentin and $\alpha$-SMA; however, desmin-positive cells were rarely seen. Along with eosinophils that have been considered to be a possible source of TGF- $\beta 1$ [41], this study shows that macrophages also participate in fibrosis associated with liver fluke infection in cattle, in relation to development of myofibroblasts expressing vimentin and $\alpha$-SMA.

ACKNOWLEDGMENT. This work was supported in part by JSPS KAKENHI Grant numbers 24.02095, 18380188 and 22380173.

\section{REFERENCES}

1. Andrews, S. J. 1999. The life-cycle of Fasciola hepatica. pp. 1-29. In: Fasciolosis (Dalton, J. P. ed.), CAB International, Oxford. 
2. Bataller, R. and Brenner, D. A. 2005. Liver fibrosis. J. Clin. Invest. 115: 209-218. [Medline]

3. Beaussier, M., Wendum, D., Schiffer, E., Dumont, S., Rey, C., Lienhart, A. and Housset, C. 2007. Prominent contribution of portal mesenchymal cells to liver fibrosis in ischemic and obstructive cholestatic injuries. Lab. Invest. 87: 292-303. [Medline] [CrossRef]

4. Brancato, S. K. and Albina, J. E. 2011. Wound macrophage as key regulators of repair: origin, phenotype, and function. Am. $J$. Pathol. 178: 19-25. [Medline] [CrossRef]

5. Clouston, A. D., Powell, E. E., Walsh, M. J., Richardson, M. M., Demetris, A. J. and Jonsson, J. R. 2005. Fibrosis correlates with a ductular reaction in hepatitis C: roles of impaired replication, progenitor cells and steatosis. Hepatology 41: 809-818. [Medline] [CrossRef]

6. Damoiseaux, J. G., Dopp, E. A., Calame, W., Chao, D., MacPherson, G. G. and Dijkstra, C. D. 1994. Rat macrophage lysosomal membrane antigen recognized by monoclonal antibody ED1. Immunology 83: 140-147. [Medline]

7. Dranoff, J. A. and Wells, R. G. 2010. Portal fibroblasts: unappreciated mediators of biliary fibrosis. Hepatology 51: 1438-1444. [Medline] [CrossRef]

8. Fabriek, B. O., Dijkstra, C. D. and van den Berg, T. K. 2005. The macrophage scavenger receptor CD163. Immunobiology 210: 153-160. [Medline] [CrossRef]

9. Friedman, S. L. 2000. Molecular regulation of hepatic fibrosis, an integrated cellular response to tissue injury. J. Biol. Chem. 275: 2247-2250. [Medline] [CrossRef]

10. Gleiberman, A. S., Encinas, J. M., Mignone, J. L., Michurina, T., Rosenfeld, M. G. and Enikolopov, G. 2005. Expression of nestin-GFP transgene marks oval cells in the adult liver. Dev. Dynam. 234: 413-421. [CrossRef]

11. Golbar, H. M., Izawa, T., Murai, F., Kuwamura, M. and Yamate, J. 2012. Immunohistochemical analyses of the kinetics and distribution of macrophages, hepatic stellate cells and bile duct epithelia in the developing rat liver. Exp. Toxicol. Pathol. 64: 1-8. [Medline] [CrossRef]

12. Golbar, H. M., Izawa, T., Yano, R., Ichikawa, C., Sawamoto, O., Kuwamura, M., LaMarre, J. and Yamate, J. 2011. Immunohistochemical characterization of macrophages and myofibroblasts in $\alpha$-naphthylisothiocyanate (ANIT)-induced bile duct injury and subsequent fibrogenesis in rats. Toxicol. Pathol. 39: 795-808. [Medline] [CrossRef]

13. Graversen, J. H., Madsen, M. and Moestrup, S. K. 2002. CD163: a signal receptor scavenging haptoglobin-hemoglobin complexes from plasma. Int. J. Biochem. Cell Biol. 34: 309-314. [Medline] [CrossRef]

14. Hautekeete, M. L. and Geerts, A. 1997. The hepatic stellate (Ito) cell: its role in human liver disease. Virchows Arch. 430: 195-207. [Medline] [CrossRef]

15. Haworth, R., Platt, N., Keshav, S., Hughes, D., Darley, E., Suzuki, H., Kurihara, Y., Kodama, T. and Gordon, S. 1997. The macrophage scavenger receptor type A is expressed by activated macrophages and protects the host against lethal endotoxic shock. J. Exp. Med. 186: 1431-1439. [Medline] [CrossRef]

16. Hinz, B., Phan, S. H., Thannickal, V. J., Galli, A., BochatonPiallat, M. L. and Gabbiani, G. 2007. The myofibroblast: one function, multiple origins. Am. J. Pathol. 170: 1807-1816. [Medline] [CrossRef]

17. Ide, M., Kuwamura, M., Kotani, T., Sawamoto, O. and Yamate, J. 2005. Effects of gadolinium chloride $\left(\mathrm{GdCl}_{3}\right)$ on the appearance of macrophage populations and fibrogenesis in the thioacetamide induced rat hepatic lesions. J. Comp. Pathol. 133:
92-102. [Medline] [CrossRef]

18. Ide, M., Yamate, J., Machida, Y., Sawamoto, O., Nakanishi, M., Kuwamura, M., Kotani, T. and Sakuma, S. 2002. Macrophage populations, myofibroblastic cells, and extracellular matrix accumulation in chronically-developing rat liver cirrhosis induced by repeated injection of thioacetamide. J. Toxicol. Pathol. 15 19-29. [CrossRef]

19. Inagaki, Y. and Okazaki, I. 2007. Emerging insights into Transforming growth factor $\beta$ Smad signal in hepatic fibrogenesis. Gut 56: 284-292. [Medline] [CrossRef]

20. Jafri, M., Donnelly, B., Bondoc, A., Allen, S. and Tiao, G. 2009. Cholangiocyte secretion of chemokines in experimental biliary atresia. J. Pediatr. Surg. 44: 500-507. [Medline] [CrossRef]

21. Köhler, C. 2007. Allograft inflammatory factor-1/Ionized calcium-binding adapter molecule 1 is specifically expressed by most subpopulations of macrophages and spermatids in testis. Cell Tissue Res. 330: 291-302. [Medline] [CrossRef]

22. Kusiluka, L. and Kambarage, D. 1996. Diseases of small ruminants in sub-Saharan Africa: A hand book on common diseases of sheep and goats in sub-Saharan Africa. VETAID, Midlothian.

23. Lazaridis, K. N., Strazzabosco, M. and LaRusso, N. F. 2004. The cholangiopathies: disorders of biliary epithelia. Gastroenterology 127: 1565-1577. [Medline] [CrossRef]

24. Lin, W. R., Lim, S. N., McDonald, S. A., Graham, T., Wright, V. L., Peplow, C. L., Humphries, A., Kocher, H. M., Wright, N. A., Dhillon, A. P. and Alison, M. R. 2010. The histogenesis of regenerative nodules in human liver cirrhosis. Hepatology 51: 1017-1026. [Medline] [CrossRef]

25. Magness, S. T., Bataller, R., Yang, L. and Brenner, D. A. 2004. A dual reporter gene transgenic mouse demonstrates heterogeneity in hepatic fibrogenic cell populations. Hepatology 40 1151-1159. [Medline] [CrossRef]

26. Marcos, L. A., Terashima, A. and Gotuzzo, E. 2008. Update on hepatobiliary flukes: fascioliasis, opisthoschiasis and clonorchiasis. Curr. Opin. Infect. Dis. 21: 523-530. [Medline] [CrossRef]

27. Marcos, L. A., Terashima, A., Yi, P., Andrade, R., Cubero, F. J., Albanis, E., Gotuzzo, E., Espinoza, J. R. and Friedman, S. L. 2011. Mechanisms of liver fibrosis associated with experimental Fasciola hepatica infection: roles of FAS2 proteinase and hepatic stellate cell activation. J. Parasitol. 97: 82-87. [Medline] [CrossRef]

28. Marcos, L. A., Yi, P., Machicado, A., Andrade, R., Samalvides, F., Sánchez, J. and Terashima, A. 2007. Hepatic fibrosis and Fasciola hepatica infection in cattle. J. Helminthol. 81: 381-386. [Medline] [CrossRef]

29. Mori, Y., Izawa, T., Takenaka, S., Kuwamura, M. and Yamate, J. 2009. Participation of functionally different macrophage populations and monocyte chemoattractant protein-1 in early stages of thioacetamide-induced rat hepatic injury. Toxicol. Pathol. 37: 463-473. [Medline] [CrossRef]

30. Ngategize, P. K., Bekele, T. and Tilahun, G. 1993. Financial losses caused by ovine fascioliasis in the Ethiopian Highlands. Trop. Anim. Health. Prod. 25: 155-161. [CrossRef]

31. Novo, E., di Bonzo, L. V. and Cannito, S. 2009. Hepatic myofibroblasts: a heterogeneous population of multifunctional cells in liver fibrogenesis. Int. J. Biochem. Cell Biol. 41: 2089-2093. [Medline] [CrossRef]

32. Ohsawa, K., Imai, Y. and Kanazawa, H. 2000. Involvement of Iba1 in membrane ruffling and phagocytosis of macrophages/ microglia. J. Cell Sci. 113: 3073-3084. [Medline]

33. Parker, G. A. and Picut, C. A. 2005. Liver immunobiology. Toxicol. Pathol. 33: 52-62. [Medline] [CrossRef]

34. Penz-Österreicher, M., Österreicher, C. H. and Trauner, M. 2011. 
Fibrosis in autoimmune and cholestatic liver disease. Best Pract. Res. Clin. Gastroenterol. 25: 245-258. [Medline] [CrossRef]

35. Platt, N., Haworth, R. and Darley, L. 2002. The many roles of the class A macrophage scavenger receptor. Int. Rev. Cytol. 212: 1-40. [Medline] [CrossRef]

36. Polfliet, M. M., Fabriek, B. O. and Daniels, W. P. 2006. The rat macrophage scavenger receptor CD163: expression, regulation and role in inflammatory mediator production. Immunobiology 211: 419-425. [Medline] [CrossRef]

37. Ramadori, G. and Saile, B. 2004. Portal tract fibrogenesis in the liver. Lab. Invest. 84: 153-159. [Medline] [CrossRef]

38. Richardson, M. M., Jonsson, J. R., Powell, E. E., Brunt, E. M., Neuschwander-Tetri, B. A., Bhathal, P. S., Dixon, J. B., Weltman, M. D., Tilg, H., Moschen, A. R., Purdie, D. M., Demetris, A. J. and Clouston, A. D. 2007. Progressive fibrosis in nonalcoholic steatohepatitis: association with altered regeneration and a ductular reaction. Gastroenterology 133: 80-90. [Medline] [CrossRef]

39. Rockey, D. C. and Chung, J. J. 1998. Reduced nitric oxide production by endothelial cells in cirrhotic rat liver: endothelial dysfunction in portal hypertension. Gastroenterology 114: 344-351. [Medline] [CrossRef]

40. Schuppan, D. and Afdhal, N. H. 2008. Liver cirrhosis. Lancet 371: 838-851. [Medline] [CrossRef]

41. Shen, Z. J., Esnault, S., Rosenthal, L. A., Szakaly, R. J., Sorkness, R. L., Westmark, P. R., Sandor, M. and Malter, J. S. 2008. Pin1 regulates TGF-betal production by activated human and murine eosinophils and contributes to allergic lung fibrosis. $J$. Clin. Invest. 118: 479-490. [Medline]

42. Song, L., Lee, C. and Schindler, C. 2011. Deletion of the murine scavenger receptor CD68. J. Lipid Res. 52: 1542-1550. [Medline] [CrossRef]

43. Strieter, R. M., Gomperts, B. N. and Keane, M. P. 2007. The role of CXC chemokines in pulmonary fibrosis. J. Clin. Invest. 117: 549-556. [Medline] [CrossRef]

44. Suzuki, H., Kurihara, Y., Takeya, M., Kamada, N., Kataoka, M., Jishage, K., Sakaguchi, H., Kruijt, J. K., Higashi, T., Suzuki, T., van Berkel, T. J., Horiuchi, S., Takahashi, K., Yazaki, Y. and Kodama, T. 1997. The multiple roles of macrophage scavenger receptors (MSR) in vivo: resistance to atherosclerosis and susceptibility to infection in MSR knockout mice. J. Atheroscler. Thromb. 4: 1-11. [Medline]

45. Tanaka, M., Itoh, T., Tanimizu, N. and Miyajima, A. 2011. Liver stem/progenitor cells: their characteristics and regulatory mechanisms. J. Biochem. 149: 231-239. [Medline] [CrossRef]

46. Tanimoto, T., Shirota, K., Ohtsuki, Y. and Araki, K. 1998. Eosinophilic proliferative pylephlebitis in the liver of Japanese beef cattle with fascioliasis. J. Vet. Med. Sci. 60: 1073-1080. [Medline] [CrossRef]

47. Wynn, T. A. and Barron, L. 2010. Macrophages: master regulators of inflammation and fibrosis. Semin. Liver Dis. 30: 245-257. [Medline] [CrossRef]

48. Wynn, T. A., Thompson, R. W., Cheever, A. W. and MentinkKane, M. M. 2004. Immunopathogenesis of schistosomiasis. Immunol. Rev. 201: 156-167. [Medline] [CrossRef]

49. Yoshioka, K., Enaga, S., Taniguchi, K., Fukushima, U., Uechi, M. and Mutoh, K. 2004. Morphological characterization of ductular reactions in canine liver disease. J. Comp. Pathol. 130: 92-98. [Medline] [CrossRef]

50. Young, N. D., Jex, A. R., Cantacessi, C., Hall, R. S., Campbell, B. E., Spithill, T. W., Tangkawattana, S., Tangkawattana, P., Laha, T. and Gasser, R. B. 2011. A portrait of the transcriptome of the neglected trematode, Fasciola gigantica-biological and biotechnological implications. PLoS Negl. Trop. Dis. 5: e1004. [Medline] [CrossRef] 